\title{
Transformation of traditional HRM practices in Japanese manufacturers in globalizing economy
}

\author{
Tetsuhiro Kishita * \\ Ryukoku University, Kyoto, Japan
}

\section{Keywords \\ Traditional HMR practices \\ Large Japanese manufacturers \\ Institutional theory \\ Organizational inertia \\ Transformation}

Received: 12 March 2019

Accepted: 10 June 2019

Published: 26 August 2019

\begin{abstract}
While the drastic changes in the business environment surrounding Japanese companies gave them huge pressures to change their management systems and practices, the magnitudes of those changes are different from respective practices. The purpose of this research is to examine why and how the traditional Human Resource Managment (HRM) practices of large Japanese manufacturers stayed unchanged or have been changing in the past two decades. For this research a question is taken theoretical and case-study approach. Based on institutional theories, we present hypothetical propositions to explain why some practices change and others do not. The related cases are provided to enhance the robustness of the propositions' explanatory power with findings that inertia of HRM practices in large Japanese manufacturers is likely to stem from strong pressures of normative and culturalcognitive elements inside the organizations; and transformation of HRM practices in those manufacturers tends to arise from increasing pressures from political, functional and social factors in the model of deinstitutionalization. The findings in this research imply that policy makers should make strategies to promote new technologies in Japanese industries and enhance the language ability of Japanese workers to change the traditional HR practice to more suitable ones in the globalizing economy.
\end{abstract}

(c) 2019 The Author(s). Published by TAF Publishing.

\section{INTRODUCTION}

Traditional Japanese employment practices refer to their celebrated practices of long-term continuous employment with a seniority-based wage system and in-house job training. For nearly three decades during the post-World War II period, Japanese firms had an implicit employment contract with their workers, who were given seniority-based wage and extensive in-company training for several kinds of jobs to provide them with job security until retirement around their sixty.

Amidst the economic downturn in the 1990s after the assets inflated economy, however, some Japanese companies began to reduce the number of their employees and the number of non-regular workers without job security increased. According to a survey of Health, Labor and Welfare Ministry of Japan, the ratio of non-regular to all the employees in the country was still around 20 percent in the 1980 s, but the number of non-regular employees sur- passed 10 million and the ratio went up to 24.9 percent at the end of the 1990s. Because of those situations, some researchers judged the Japanese-style employment system demised. For example, Ahmadjian and Robinson (2001) examined the role of downsizing in the deinstitutionalization of permanent employment among publicly listed companies in Japan between 1990 and 1997. They found that although large, old, wholly domestically owned, and highreputation Japanese firms were resistant to downsizing at first, they finally had no choice but to execute downsizing spread across the population.

The ratio of non-regular employees in the country increased in the 2000s. The labor ministry published the survey of work arrangements in January 2015. It says that the ratio of non-regular employees in the private sector is 40.5 percent. The report ascribes the increasing ratio to the influx of workers who had been working as independent workers in agriculture sectors and abolished one-man businesses.

\footnotetext{
* corresponding author: Tetsuhiro Kishita

†email: tetsuirokishita@gmail.com
} 
In other words, the increasing number and ratio of nonregular employees not necessarily mean the demise of the traditional Japanese-style employment. As far as traditional manufacturers in large sizes, we may say that some of the traditional Japanese employment practices, especially lifetime employment, still are maintained. Most the new graduates in Japan start to work for large companies with a termless contract every April and they take it for granted. On the other hand, several reports or researches of the economic press show that some leading companies in Japan have been changing their payment policies, especially from seniority-based wages to job-based wages in the middle of the development of globalizing economy and the IT innovation. Although we now have some knowledge about the facts of these changes and non-changes in HRM practices of the companies in the country, it seems that there is a lack of research on the rationale for why some of the traditional Japanese employment practices still linger and why others are innovated. Building on institutional theory, our paper aims to fill this research gap with a theoretical explanation for why some large Japanese manufacturers maintain those HRM practices but why and how others change them.

The perspective of institutionalization and deinstitutionalization (Mahdieh, 2015; Oliver, 1992) gives us a robust theoretical foundation for our research because it is specialized in exploring the processes by which structures, including schemes, rules, norms, and routines, become established as authoritative guidelines for social behavior or traditional practices. Since business organizations in a country are deeply embedded in their local institutional environments as well as global business environments, their management practices are often either direct reflections of, or responses to rules, values, norms, and belief built in their larger contexts. Within the model of institutional theory, we provide some anecdotal cases of established Japanese manufacturing companies. With producing propositions on how traditional HRM practices in large Japanese manufacturers linger or change, our study contributes to extend the logic of institutionalization and deinstitutionalization.

\section{LITERATURE REVIEW AND THEORETICAL FOUNDA- TION}

\section{Institutional Theory}

The fundamental question in institutional theories is "why there is such startling homogeneity of organization forms and practices" (DiMaggio \& Powell, 1983). For the inquiry, the theories give a basic thesis that once formed is de-facto standards of organizational forms, rules and practices which people believe to be legitimate, organiza- tions should be not only rational in economic or functional performances but also conform to the de-facto standard for their survival or growth (Meyer \& Rowan, 1977; Rijal, 2016). DiMaggio and Powell (1983) argue the isomorphic mechanism in which organizations with the same environment will choose the same practices or strategies and become similar with one another over time due to an overall pressure to conform to the institutional norms within the environment. They identify three general mechanisms of isomorphism: coercive, mimetic and normative isomorphism. Coercive isomorphism occurs when organizations are compelled to adopt the most pervasive structures or rules. Mimetic isomorphism arises when one organization copies another, often because of uncertainty. Normative isomorphism results from the fact that organizations make the same decisions on choosing practices because professionals in organizations are likely to be educated in similar ways. On the other hand, regulative systems, normative systems, cultural-cognitive systems-each of these elements have been identified by one or another social theorist as the vital ingredient of institutions. These three systems called the three pillars of institutions are summarized in Table 1. In the table, the columns contain the three elements and the rows define some of the principal dimensions along which assumptions vary and arguments arise among theorists emphasizing one or another element (Scott, 2013). Note that mechanisms of the theory element in each pillar are closely related to one of institutional isomorphism which DiMaggio and Powell (1983) pointed out.

Once socially embedded systems in a filed become institutionalized, they tend to be stabilized, because organizations may try to change constantly; but after a certain point in the structuration of an organizational field, the aggregate effect of individual change is to lessen the extent of diversity within the field (Powell \& DiMaggio, 2012; Tsai \& Tsai, 2017). In addition, Zucker (1977) claims that "institutionalization often occurs accidentally, as a by-product of the creation of other structures; deinstitutionalization is seldom accidental. Once institutionalized, structure or activity may be maintained without further action: institutionalized elements become embedded in networks, with a change in any one element resisted because of the changes it would entail for all the interrelated network elements." For example, Keiretsu corporate groups in Japan, Chaebol in Korea, and Jituanqiye in Taiwan are isomorphisms in the fact that they are corporate groups created by companies in various industries. However, they are slightly different corporate groups that are influenced by regulative, normative and cultural-cognitive factors. The keiretsu corporate 
group in Japan is a firm community type, the Korean Chaebol is a type of corporate patrimonialism, and the Taiwan corporate group is a family network type of corporate group (Orru, Biggart, \& Hamilton, 1997; Silva \& Madushani, 2017). Fashionable management practices are also institutional- ized. Perkmann and Spicer (2008) explore how transitory management fashions become institutionalized. The study postulates that fashionable management practices acquire permanence when they are anchored within field-wide institutions.

TABLE 1. Three pillars of institutions

\begin{tabular}{|c|c|c|c|}
\hline & Regulation & Normative & Cultural-Cognitive \\
\hline Basis of compliance & Expedience & Social obligation & $\begin{array}{l}\text { Take-for-granted } \\
\text { Shared understanding }\end{array}$ \\
\hline Basis of order & Regulative rules & Biding expectations & Constitutive schema \\
\hline Mechanisms & Coercive & Normative & Mimetic \\
\hline Logic & Instrumentality & Appropriateness & Orthodoxy \\
\hline Indicators & Rules/Laws/Sanctions & Certification/Accreditation & $\begin{array}{l}\text { Common belief/Shared } \\
\text { logics of action/Isomorphism }\end{array}$ \\
\hline Affect & Fear Guilt/ Innocence & Shame/Honor & Certainty/Confusion \\
\hline Basis legitimacy & Legally sanctioned & Normally governed & $\begin{array}{l}\text { Comprehensible/Recognizable } \\
\text { Culturally supported }\end{array}$ \\
\hline
\end{tabular}

Source: Scott (2013)

On the other hand, Oliver (1992) defines the process of deinstitutionalization as being "the process by which the legitimacy of an established organizational practice erodes or discontinues. Specifically, deinstitutionalization refers to the de-legitimation of an established original practice or procedure as a result of organizational challenges to or failure of an organization to reproduce previously legitimated or taken-for-granted organizational actions." To put it simply, deinstitutionalization is the abandonment of widespread, taken-for-granted practices (Maguire \& Hardy, 2009). Outright abandonment of an institutionalized practice represents the extreme case of deinstitutionalization (Scott, 2013). Therefore, the abandonment of Japanese companies' practice of permanent employment is a form of deinstitutionalization.

Oliver (1992) points out three drivers who work to cause change within organizations: functional, political and social pressures. Functional pressures increase when changes in technology cause poor performance of some traditional practices and reduce their legitimacy, which may lead to increased consideration of alternative policies. Political pressures arise from increasing problems of organizational performance and from shifts in interests or underlying power distributions that provide support for existing institutional arrangements. Social pressures are those that cause normative fragmentation which means a loss of cultural consensus or agreement among organizational members, causing divergent or discordant beliefs and practices.

\section{Traditional HRM Practices of Large Japanese Manufac- turers}

The traditional Japanese-style HRM has three pillars: longterm continuous employment (often called life-time employment), a seniority-based wage system, and in-house training. In this paper, we focus on long-term employment practice and the seniority-based wage system.

The long-term continuous employment practices can be found not only in Japanese firms but also in European countries and the U.S. However, while labor markets in western countries have more fluid workforces as part of a bipolar structure of employment, the open market for labor in Japan actually have existed only for new graduates. Blessed employees with long-tern job security change their jobs in internal labor markets, namely in the companies or the same companies' groups.

Abegglen (1958) firstly introduced a long-term employment contract between Japanese manufacturers and their employees. He surveyed Japanese manufacturers in the late 1950s and found out that most of the firms in the country provided their workers unlimited term employment contracts which he referred to as "life-time commitment." He explains the reason why the corporate managers in the country provide such a generous job-security by quoting their story that their employees believe that employers have to protect the lives of workers and they have a mission to revive the country's economy. According to his explanation, the practice of life-time employment had been formed 
in the 1950s based on a normative (moral) consciousness sense reflecting a kind of social responsibility of business leaders who had a belief that we, Japanese people should help each other to survive because "we have nothing and we all are utterly poor". Therefore, we can see that the life-time employment system was initiated based on the normative pressure in society in the 1950 s.

The life-time employment policy became legally institutionalized through an accumulation of judicial judgments in the 1970s when Japanese manufacturers tried to reduce the number of workers in the face of the two oil crises. In this decade, workers and companies in the country had legal disputes over employee layoffs. Many court rulings supported workers' claims, which established doctrine of abuse of the right of dismissal. The labor law in Japan permits business firms to dismiss their employees in principle. However, the court rulings make such sever conditions on their dismissal for the purpose of reorganization: there must exist plausible reason for dismissal; firms have to take some actions for avoiding dismissal; firms must not choose particular employees to fire; and firms have to give a sufficient explanation to employees to lose jobs and the labor union which they belong to. We can assume that the lifetime employment contract became a legally institutionalized practice through many workers' winning lawsuits in the 1970s. Actually, the ratios of workers' winning lawsuits over the dismissal disputes are shifting between 50 - 60 percent from the middle of the 1960s to the beginning of the 1990s and hovering at a high 70 percent in the late 1990s. On the other hand, when Japan Productivity Center did a survey over firms with more than one thousand employees in 1979, the center asked the corporate managers the following question: "what kind of employment packages do you want to provide for the employees in your company ten years after now?" Majority of corporate managers (67.7 percent) answers that they want to provide them with such a life-time employment package as permits workers to continue working from recruiting through mandatory retirement; and more than 80 percent of the corporate managers prefer a life-time employment package because the package is not so much effective but so firmly fixed in the society that they take it for granted. Judging from this survey, we can see that the life-time employment practice became a kind of cultural-cognitive system in Japanese society later in the 1970s.

As explained above, although many people in the country seem to feel that the lifetime employment system has demised because of an increasing number of non-regular employees in this decade, the system still exists as an em- bedded system in large manufacturers. A lot of new graduates with good academic back grounds take a lifetime employment package for granted and would like to commence employment in a big company.

Another element of traditional employment practice is the seniority-based wage system. In the 1950s just after the end of World War II, all the people in Japan were struggling for survival. Therefore, most of the companies paid their workers subsistence wages which made ends meet for all the members of their family. Since the money they needed to feed their family usually increased with their age, most of the workers in those days were paid based on their age. The seniority-based wage system is also analogous to trends found in Europe and the U.S. where wage increases as age rises. Compared with Europe and the U.S., however, the agerelated wage gap in Japan is much greater. Furthermore, wages plateau at age 40 in Europe and the U.S., whereas in Japan it is common for wages to continue to increase at the age of middle $50 \mathrm{~s}$.

In the 1960s, some of the large firms introduced from the United State a job wage system in which wages of respective jobs is determined based a rigid job analysis. The process of a new wage system seems to be a mimetic one. However, it is more appropriate that we regard it as normative one because corporate managers of Japanese firms in those days thought that they were still behind in their management systems and practices, and they believed that systems and practices of American companies were so beautiful that they were the models which they should introduce. The American wage system, however, did not fit the working styles of Japanese employees who change jobs and workplaces regularly every few years. For example, although such big ironworks like Yawata steel, Fuji steel and Nippon Koukan in those days introduced the job wage system, they grew their business so rapidly in the 1960s that they had to transfer often their employees around the country. As a result, it became difficult for them to pay their employees based on jobs because employees' jobs changed so often in their transfers.

It just so happened at the beginning of the 1960s that the Nikkeiren, Japan Federation of Employers' Associations, advocated a pay system called shokunou-chingin. In this system, workers' wages are paid based on their ability to perform jobs, and the ability of each employee is evaluated based on the ability-based grade system. The shokunouchingin system became a rational payment system for large Japanese manufacturers which customarily moved their employees within intra-company because the payment system is not based on jobs themselves but individual employ- 
ees' ability. After that, more and more Japanese companies introduced the payment system which became the defacto standard of wage system in the 1970s and 1980s in the country.

The annual income of a typical employee in large Japanese firms consists of twelve-monthly salaries and bonuses which usually are provided twice in a year. Although the monthly salary is composed of a seniority-based portion and an ability-based one, the latter part is likely to be paid based on the length of employees' services because the process of ability evaluation involves a lot of consumption of time and money. Furthermore, although bonuses are paid officially based on the evaluation of employees' capability, commitment, and performance, actual amounts of them tend to be paid based on seniority-basis for the same reason. Average workers in large firms in the country are usually paid from three to five monthly salaries as bonuses in a year. As a result, the wages of ordinary workers in large Japanese firms became institutionalized to be what we call seniority-based ones. The institutionalization process of the seniority-basis wage system is a mimetic one because many firms introduced the system that the authoritative Nikkeiren recommended.

However, since the 1990s after the bubble economy collapsed, more and more Japanese companies began to change such an ability-based wage system because it had been used so heavily based on seniority basis that the wage burden became huge for employees of the baby boomer generation whose ages reached at around 50s in the 1990s. Some companies began to introduce a new payment system called yakuwari-kyu in Japanese. This system has too many varieties from company to company to explain with plain words. In this system, employers measure two elements: roles and performances. Roles are the extent to which employers expect a worker to play in the process of addedvalue creation. Performances are measured by how much the roles of respective employees are performed. In other words, they try to evaluate the size of the outcome of jobs which shows the degree of task target achieved. They also changed the bonus policy. Some companies began to pay bonuses to their employees based on employees' competency and job performance instead of a merit-rating system. We can see that there are changing and unchanging ones among the traditional HRM systems and practices in large Japanese firms. While the traditional employment contracts still are unchanged as long-term ones, wage systems have been changing since the 1990s from seniority-basis ones to the job-outcome-oriented ones.

\section{THEORETICAL FRAMEWORK AND PROPOSITIONS}

From the viewpoint of the institutional theory (Greenwood \& Hinings, 1996), we can see it as stability or inertia of organizational practices that large Japanese manufacturers still adhere to the lifetime employment policy despite the drastic changes in business environment after the 1990s; and it as deinstitutionalization or changes of organizational practices that they shift the wage system from a seniority based one to jobs' outcome oriented one. Building on these perspectives, we provide institutional models for stability and changes in organizational practices.
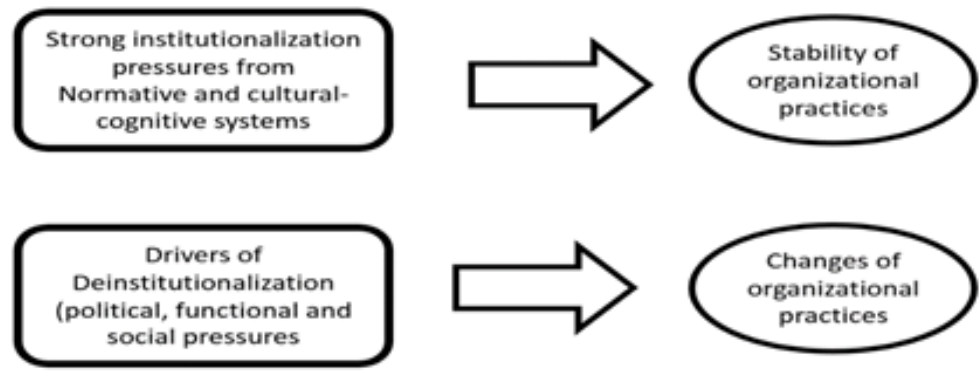

FIGURE 1. Institutional models for stability/changes of organizational practices

\section{Pressures to Embed Management Practices in Organi- zations}

Strong institutionalizing pressures can congeal management practices in organizations. Let us examine how each of institutionalizing pressures from regulative, normative and cultural-cognitive systems embeds the long-term employment in Japanese companies. Among these three types of pressures, the one from the regulative system has smaller effects on organizational inertia than those two from normative and cultural-cognitive systems because the congealment of management practices is an interactive event inside an organization and the pressure from regulative systems is generally one from the outside of it. Although many legal judgments rejected the abuse of right of dismissal for the purpose of companies' reorganization, many companies ignored such legal judgments and reduced the number of 
workforces for the purpose of reorganization by soliciting voluntary retirement. Therefore, we do not take the effect of regulative pressure into consideration in examining the organizational inertia.

Pressures from normative systems can have a great effect on organizational inertia. Normative systems include both values and norms. Values are conceptions of the preferred or the desirable together with construction of standards to which existing structures or behaviors can be compared and assessed. Norms specify how things should be done; they define legitimate means to pursue valued ends. Normative systems define goals or objectives like making a profit but also designate appropriate ways to pursue them like conceptions of fair business practices (Scott, 2013). Therefore, the pressure from normative systems is a sense of social obligation which makes organizational leaders shameful if they do not choose to execute the common and prevailing practices in an organizational field. The legitimacy for taking those practices is morally governed in the field. When we interpret this logic in our discussion context, we can say that corporate managers' sense of social obligation influences the maintenance of long-term employment contracts with their employees. Many corporate managers of large Japanese manufacture often say that the employment maintenance is a kind of social responsibility of large firms.

However, it is too native to believe the logic that large Japanese manufacturers maintain the lifetime employment practice just because it is a kind of Corporate Social Responsibility (CSR) of the large firms. We should know that we can ensure long-term job security for people not just by internal labor markets (or lifetime employment in a company) but also by highly fluid labor markets if new industries replace old ones and absorb redundant labor forces. In addition, the rational choice of management practices should be firstly based on its effectiveness on corporate performance, and secondly on CSR. Therefore, when corporate managers say that the job security is a kind of CSR, we should know that the maintenance of employment has some effectiveness for corporate profits. The effectiveness of the lifetime employment on corporates' performance depends on the fact that they can use the firm-specific skills which workers in the company accumulate on the premise of long-term employment. In other words, the lifetime employment system is a system which promotes the employees' commitment to acquiring such firm-specific skills. However, at the same time companies have some risk with the lifetime employment practice that they must continue to employ those workers even when they do not need their employees' firm-specific skills anymore. It depends on the characteristics of dominated technology in industries whether advantages outweigh disadvantages in lifetime employment system of the Japanese manufacturers. The lifetime employment practice produces such good effect as employees' higher commitment in the industry with optimizing technology in which workers make and assemble many parts with complementarity in a team. On the other hand, in the industry in which production processes are standardized with modularized parts, the lifetime employment practice would not be so effective because the firm-specific skills of workers in their long-term service in the firms are not so important. Therefore, corporate leaders in the industry with optimizing technology regard lifetime employment as a kind of CSR more strongly than those in the industry with standardized technology dominated. Put the above arguments together:

Proposition 1: Corporate managers in the industry with optimizing technology are more likely to maintain the lifetime employment policy than those in the open architecture industry with modularization technology.

Pressures from the cultural-cognitive system have an effect on organizational stability in the following way: "... compliance occurs in many circumstances because other types of behaviors are inconceivable; routines are followed because they are taken for granted as "the way we do things." The prevailing logic employed to justify conformity is that of orthodoxy, the perceived correctness and soundness of the ideas underlying action" (Scott, 2013). To put it simply, a set of practices is embedded to be stabilized in organizations because the members of the organization support its robust legitimacy culturally. When we interpret this theoretical logic in our discussion context, we can say that many members of large Japanese manufacturers have taken the long-term employment practice for granted and enjoyed the benefits of that practice as bested rights (Jacoby, 2018). However, the interest groups who can enjoy most of these bested rights in the firms are just those core (male) employees with a university degree. In fact, since companies cannot promote all the core employees to corporate managers, they dispatch most of those employees to the subsidiaries or affiliated companies in their company group. In other words, they secure their mainline employees' jobs in their whole life in companies of their corporate group. The lifetime employment is most beneficial for male whitecollar workers with a university degree in the parent company. This employment system works under their tacit understanding that they should work hard in promotion races in the parent and the rule of the race is up or go to subsidiaries. Based on the above discussion: 
Proposition 2: The lifetime employment practices are more likely to be stabilized in firms which have a relative small number of selected mainline employees and many subsidiaries for them to be dispatched.

\section{Pressures to Change Management Practices in Organi- zations}

As we explained, according to Oliver (1992), there exist three types of pressures toward deinstitutionalization: functional, political, and social pressures. We examine how each type of pressure has an effect on the change of the traditional wage system one by one. Firstly, political pressure is a driver to change institutionalized practices in organizations. Political pressures are the ones that result from changes in underlying power distributions that provide support for existing institutional arrangements. A shift of corporate managers due to ownership changes is a typical one of these political pressures (Olcott, 2009). The traditional HRM practices in large Japanese firms have been formed in the society of their mainline employees. Most of corporate managers in large Japanese manufacturers are likely to be a former employee in the firm. It is natural for those corporate managers who are promoted from an employee to protect interests of the employees in their company. However, when the company plunges into a financial trouble and finances new capital from a non-traditional root, there will be a strong possibility to accept a new corporate manager from outside the world. Such a new corporate manager who comes from outside the company, especially from a foreign country, tend not to share the corporate culture fostered so far in the company. In this situation, the political pressure will increase for changes of organizational practices institutionalized so far. Based on the above discussions:

Proposition 3: The likelihood or intensity of changing traditional HMR practices will be higher in Japanese firms that have a foreigner as their CEO who is invited from outside the firm than those that have a CEO who promoted from an employee in the firm.

Secondly, the functional pressure is another driver to change the practices in organizations. This type of pressure can arise from changing consumer preferences (Scott, 2013). When consumer preferences change rapidly, manufacturers must provide new products quickly with new technology. Under this situation, the companies must provide their engineers with a market-oriented incentive in order not to lose the markets. If they do not have appropriate engineers for the new markets, they have no choice but to hire new engineers from outside the companies. In any of these cases, the traditional system of payment based on seniority is not appropriate. They need a new payment system with which employers can motivate engineers to invent new products that meet the changing consumer preferences. Therefore:

Proposition 4: Manufacturers tend to change traditional HRM practices more intensively in the industries in which technology and/or consumer preferences change rapidly. Finally, the social pressure is a third driver to change the practices in organizations. Social pressures associated with differentiation of groups and increasing fragmentation of normative consensus, causing divergent or discordant beliefs and practices (Scott, 2013) and a radical change which is likely to occur in organizational fields that have strong, local market forces and strong but heterogeneous institutional forces (D'aunno, Succi, \& Alexander, 2000). On the other hand, Kraatz and Moore (2002) examines how the immigration of leaders possessing different skills, understandings, assumptions, and values can promote change within institutionalized organizations and fields. From our discussion context, such events like organizational differentiation and fragmentation of consensus are interpreted as increasing diversity in workplaces. Diversity in business organizations stems from increasing numbers of managers and workers who have different cultural backgrounds. For example, when Japanese firms expand their business abroad, they have to hire local people who usually do not understand the Japanese language nor culture. Furthermore, living standards and customs in foreign countries are completely different from those in Japan. Therefore, it would be difficult for Japanese firms to apply the same employment and wage policies as they have at home. They need kinds of adjustments: they may introduce new HRM practices to foreign subsidiaries; and they may change those practices at home and introduce new standardized policies to all employees in the companies at home and local countries. Therefore:

Proposition 5: Manufacturers with a high volume of business activities in foreign countries tend to change traditional HRM practices more intensively.

\section{CASE STUDY AND DISCUSSION}

To increase the explanatory power of our theoretical models for our research question, we provide some cases to support each proposition's appropriateness. The case study approach is suitable for "why" and "how" questions in new topic areas (Yin, 2017). Our research question is why some traditional HRM practices stay unchanged against pressures of institutional factors; and why and how others change in 
response to those pressures. Although the cases in the following discussions can be just circumstantial pieces of evidences, the suitable cases may enhance the robustness of the explanatory power of hypothetical propositions. While a lot of data provide statistically explanatory power to hypotheses, they cannot provide the reasons to connect the explanatory variables to explained ones. Therefore, through the following case studies are explored why and how to stabilize or change the traditional HR practices in Japanese firms.

\section{Pressure of Normative System to Stabilize Traditional Practices}

For the purpose of examining the appropriateness of Proposition 1, we take Toyota Motor Corporation as a case of the industry with optimizing technology and Uniden Corporation as a comparative case of open architecture industry. Toyota is a leading manufacturer that utilizes optimizing technology, suriawase gijutsu in Japanese, which is a key concept to success in the integral architecture industry. Toyota is famous for being a company which thinks a great deal of its employees' employment. One of the former CEO, Hisashi Okuda (president: 1995-1999) once told that Toyota would secure its employees' jobs with its entire asset of the company. The current president of the company, Akio Toyota, also declares that he is determined to maintain its domestic production in order to protect employment in the country. The idea of creating mutual benefits for both the company and the employees through the long-term contract is expressed in the company's website (Toyota, 2018).

Through our communication and dialogue with the company, we, people working for TOYOTA, strive to build and share fundamental value of "Mutual Trust and Mutual Responsibility." TOYOTA endeavors to improve its business achievements so that TOYOTA can continue to provide employment and fair and stable working conditions for each of us. Simultaneously, TOYOTA promotes a work environment in which each of us can work in a harmonious and dynamic manner. In return, each of us implements the "Toyota Code of conduct" and endeavor to fulfill our duties with integrity. By fully utilizing our ability and capabilities and cooperating with others working for TOYOTA, we continue to improve the business performance of TOYOTA.

On the other hand, Uniden Corporation is famous for a gYpsy manufacturer who continues to search for cheaper labor. Uniden Corporation is a Japanese wireless communication equipment manufacturer which was established in Chiba, Japan in 1966. The company became well-known in the 1970s with CB radios, and in the 1980s with cordless telephones, television satellite equipment, mobile radios, advanced marine electronics and radio scanners. The company manager and founder, Hideo Fujimoto, makes every decision and he seems not to have such an idea of lifetime employment in his business field. The company has been moving its production sites from one place to another in foreign countries to utilize cheaper labor since the 1970s. In his strategy, when the production firms become unprofitable, the firm should be shut down. For example, the production company established in Shenzhen, Chain in 1993 was closed in 2009, and the factory constructed in Philippine in 2005 continued its production activity only for three years. The number of employees in the company shrunk from 10,000 to 1,400 in the entire company group, and from 200 to 80 in the parent company. Many managers and workers are recruited from outside the company but not many of them stay in the company for a long time.

\section{Pressure of Cultural-Cognitive System to Stabilize Tra- ditional Practices}

In order to examine the appropriateness of the Proposition 2, let us see the numbers of subsidiaries, employees of entire group company and of the parent company (Table 2). Large Japanese manufacturers usually have a lot of subsidiaries at home and abroad. For example, Sony Corporation and Hitachi, Ltd. have more than one thousand subsidiaries. The ratios of payroll number of the parent company (unconsolidated) to the one of the entire group of companies are from 2.1 percent to 29.4 percent. Mainline male workers account for only a small portion of the entire employees at the parent company. As a result, the portion of the number of core male workers to that of the entire number of employees in the whole group companies may become very small. Therefore, these relatively small portions of the male workers may believe naturally that they are celebrated and mainline core workers and want to maintain the traditional practices which bring them vested benefits. This is a way that a small portion of mainline male workers in larger Japanese manufacturers put pressure on maintenance of traditional lifetime employment system. 
TABLE 2. Numbers of subsidiaries, employees of large Japanese manufacturers

\begin{tabular}{llllllllll}
\hline \hline & Sony & Hitachi & Toshiba & Toyota & Fujitsu & Panasonic & Honda & Shinitetsu-Sumikin & $\begin{array}{l}\text { Sumitomo Elec- } \\
\text { tronics }\end{array}$ \\
\hline $\begin{array}{l}\text { Subsidiary } \\
\begin{array}{l}\text { Consolidated } \\
\text { no.of employees }\end{array}\end{array}$ & 1,240 & 1,008 & 584 & 541 & 510 & 468 & 372 & 356 & 354 \\
$\begin{array}{l}\text { Unconsolidted } \\
\text { no.of employees }\end{array}$ & 10,500 & 37,753 & 36,601 & 68,240 & 24,112 & 51,308 & 22,399 & 24,903 & 240,865 \\
$\begin{array}{l}\text { Unconsoli- } \\
\text { dated/ }\end{array}$ & $8.0 \%$ & $11.1 \%$ & $19.5 \%$ & $19.8 \%$ & $15.4 \%$ & $20.6 \%$ & $10.7 \%$ & $29.4 \%$ & 4,984 \\
Consolidated & & & & & & & & & $2.1 \%$ \\
\hline \hline
\end{tabular}

Data: Annual reports

\section{Political Pressure on Changes in Traditional Practices}

In order to examine the appropriateness of Proposition 3, we take some cases to see whether new foreign CEOs in established large manufacturers in Japan take some actions to change their traditional practices of management.

We found some foreign CEOs began to take an office in large Japanese firms in the late 1990s. For example, Mazda has brought four foreign CEOs from Ford Motor, USA; Mitsubishi Motor accepted Rolf Eckrodt to its management board from Daimler-Chrysler AG, Germany from 2002 to 2004; and Carlos Ghosn has been managing Nissan Motor since 2000. Ghosn came from Renault SA, France. They were invited from foreign companies by Japanese firms which had financial difficulty and accepted financial supports from foreign companies. In the middle of the 2000s, Japanese firms accepted foreign corporate managers with international business experiences in their strategic process of acquiring some foreign companies for the purpose of expanding their business globally. For example, Sony had invited Mr. Howard Stringer as president of company for eight years since 2005; and Nippon Sheet Glass Company accepted two foreign corporate managers from 2008 to 2012 when the company acquired Pilkington Group Limited in the UK.

Those foreign corporate managers were invited with great expectations to reform the traditional organization in the country to be profitable. For example, Ghosn, who is called Mr. cost-cutter, initiated the Nissan Revival Plan and introduced global standard remuneration program for management employees. They are paid a fixed salary on a yearly contract system and can get bonus if they can achieve the managerial goal which is set at the beginning of the business year. The company's remuneration package for the management has nothing to do with seniority.

It is true that newly appointed foreign corporate managers put pressure to change traditional Japanese HRM systems and practices which they regard as a principal cause of a business slump in the companies. However, it is rare that those pressures can work and change those traditional HRM ones fundamentally, let alone change the business to be profitable. The success of Carlos Ghosn is said to be one of those rare cases. In the case of Nissan revival, since Mr. Ghosn was backed up by Renault SA with 43.3 percent shares of Nissan, he was able to change radically the company which was lacking enough money to survive and just waiting for a savior from outside of the company.

In most cases, although foreign corporate managers newly appointed from outside the company try to change traditional way of doing business in the country, their attempts are more likely to be a failure with resistance of organizational inertia in the companies. For example, in October 2011, British-born Michael Woodford was suddenly discharged from the CEO position of Olympus Corporation by Japanese chairman of the company when he had been in that position for six months and trying to investigate one of the biggest and longest-running loss-hiding arrangements in Japanese corporate history. It was the same board chairman who had appointed Woodford to the position and dismissed him in order not for him to disclose the true story of the scandal because he and his inner circles were involved in the scandal.

The case of Stringer of Sony is another typical case in which a foreign CEO was not able to work effectively at an established Japanese manufacturer. He had a lot of experience and expertise in the broadcasting industry, but he was said to have not understood the problems in the product lines until his last minutes at Sony. He was not able to thrust into the core of Sony's culture: producing cool electronic gadgets.

In addition, two foreign corporate managers also resigned from the board of Nippon Sheet Glass Company just because they were not to work well in the company. The first president, Briton Stuart Chambers resigned in 2009 after just 15 months, saying he would like to spend more time with his family. He is said that he was not able to get accustomed to the business culture in Japan. The second foreign president, Craig Naylor quit the company after less than two 
years in the post following fundamental disagreements with the board over strategy. Naylor was also said to be facing resistance from other officials at the firm to cutting jobs and others costs in Japan.

Non-Japanese CEOs have long been rare in Japan. Although, most of companies in the country typically own a consensus-building culture that cannot much up at all with the management ideas of business leaders from western countries. After all, pioneering foreign corporate managers who took their offices at large traditional manufactures in Japan in the past decades had difficulties understanding the culture of institutionalized organization. From the above discussion, we may say in the context of Proposition 4 that foreign corporate managers appointed from outside companies definitely try to put pressures to change the traditional Japanese management practices; however, they are not necessarily able to change them effectively because of underlying forces of antireform which are embedded in traditional organizations as an organizational inertia.

\section{Functional Pressure on Changes in Traditional Prac- tices}

For the purpose of examining the validity of Proposition 5, it is relevant to compare wage systems between companies in the electric instrument industry and those in the steel industry because technological innovation is rapid in the former industry, but it is not so in the latter industry.

In the electric instrument industry, some leading companies abandoned the traditional wage system which is based on seniority and introduces a new system in which they pay their employees based on job grades or role grades in recent years. Panasonic discontinued the traditional pay system with ability-based grade and introduced a new payment system to all the employees in October 2014. In the new system, workers are paid according to the role they are expected to play in their workplaces. Hitachi Ltd. introduced the same new system to 11 thousand employees at the manager class at the same time. Sony Corporation also replaced the traditional payment system in which some part of employees' income is based on seniority with the job grade system in which employees are paid based on the role that they are playing in their workplace. The company applies the new system to a total around ten thousand employees in the parent company of Sony Group Inc.

On the hand, Nippon Steel \& Sumitomo Metal Corporation, a leading company in the steel industry in Japan, still maintains the traditional ability-based grade system. Annual income distribution in age cohort shows that the company still pays the employees based on the length of their services (Table 1). Another leading company in the industry, JFE steel renovated its payment system in 2015. However, the company adjusted the band of grades in the traditional ability-based grade system (Daily Iron Newspaper, 2015), which means that the company still use the traditional system.

TABLE 3. Averaged annual income of employees in Nippon Steel \& Sumitomo Metal Co. (thousand Yen)

\begin{tabular}{lccccccccc}
\hline \hline Age & $20-24$ & $25-29$ & $30-34$ & $35-39$ & $40-44$ & $45-49$ & $50-54$ & $55-59$ & $60-65$ \\
Annual Income & 3,386 & 4,217 & 4,633 & 5,287 & 5,940 & 6,653 & 7,128 & 7,069 & 4,811 \\
\hline \hline
\end{tabular}

Data: Estimation from key statistics of wage structure http://www.mhlw.go.jp/english/

\section{Social Pressure on Changes of Traditional Practices}

We can take the cases of Fast Retailing, Takeda pharmaceutical company and Hitachi, Ltd. for examining the appropriateness of proposition 5: the intensity of attempts to change traditional employment practices will be higher when Japanese manufacturers more actively expand the volume of business activities in foreign countries.

Fast Retailing is a Specialty-store retailer of Private-label Apparel (SPA) company in Japan that owns UNIQLO and other five brands, accounting for 6.5 percent of the Japanese apparel market as of 2015. The company opened its first UNIQLO store in 1984 and continued to build a chain of suburban roadside stores in Japan. In the late 1990s, company began opening stores in urban locations. Subsequently, the company opened stores within prominent shopping malls, and also global flagship and hotspot stores in Ginza, Shinjuku and Osaka in Japan, and UK, China, Hong Kong, Taiwan, South Korea and other parts of Asia. By August 2015, UNIQLO International constituted approximately 44 percent of total UNIQLO sales, with 798 stores versus 841 stores in Japan (From About FAST RETAILING on the company's website). President of the company, Maso Yanai, declared his determined idea about introducing the global standard wages for all the employees in the companies all over the world in Asahi Newspaper's interview in April 2013. The principle of his idea for paying remuneration is "the same wage for the same job." He says that his idea on remuneration is based on the rapid expansion of the company's business over the world. He also says that his company's motto is "change or die" which means "grow or die" 
in the global market. He thinks that the development of economic globalization demands polarizations in both job and payment; and there will be highly-paid workers who do high-value creating jobs at one extreme and poorly-paid workers who do low-value creating jobs at the other. His idea is very clear but it practical realization is difficult. The company introduced a globally standardized wage system for executives. However, one of the corporate officers says that it is difficult to adjust such each country's difference as conditions in labor market and living standards so that the company still needs more time to apply the global standardized wage system to all the employees in the world.

The second evidential case is Takeda pharmaceutical company. The company declared in May 2005 that employee ranks would be paid based on work assignment with no relation to his or her service length in the company, and administrative executives would be paid based on job grades and job performance which they achieve. These reforms in remuneration packages were part of its internationalization strategy. The company made a five-year-term strategy to change itself from a local pharmaceutical company in Japan to a globally acting one located in Japan in 1995. To achieve this goal, the company restructured its organization by reducing the number of its employees in non-medical fields by approximately 30 percent and concentrating its resources into R\&D activity to make new drugs. These strategic reforms achieved a successful outcome. Although the company's sales amount in the domestic market did not increase in the past decade, it grew greatly in markets of US and European countries. Now the company group spans over 70 countries and regions worldwide. Takeda's net sales volume in the 2015 fiscal year is 1807.4 billion yen of which 1057.8 billion yen (61.8 percent) comes from overseas markets. This company's case shows that strategic change in traditional remuneration system can contribute to enhancing the volume of business activities in foreign countries.

Hitachi is another good example to support the appropriateness of proposition 5. Hitachi issued a press release in September 2014 that the company would change its payment package for management level employees from seniority-basis system to job-basis one in October 2015; and the company would apply the new package to all the employees in approximately 950 companies of Hitachi group. Before then, the company had paid 70 percent of an employee's entire salary based on the length of his or her service in the company and the remaining 30 percent based on job size or responsibility. The company said that the purpose of new payment policy was to enhance its overseas sales by securing high-quality human resources. The company believed that linking payment to job-size or jobresponsibility made it possible to choose and promote excellent young worker directly to high-value creating jobs and hire high-quality young people from outside the company. Although it is not clear whether its new payment policy worked well or not, the ratio of the company's oversea sales to its entire sales amount increased 41 percent to 48 percent in 2015 fiscal year.

\section{CONCLUSION}

This research provides a logical explanation of the transformational process of the traditional HRM practices of the Japanese manufacturers in the environmental changes from the perspective of the institutional theory. We attempt to explain theoretically the process in which some manufacturers maintain the lifetime employment policy from two institutionalizing drivers. We also try to give a theoretical explanation of the deinstitutionalization process of traditional seniority-based wages of large Japanese manufacturers. We provide five hypothetical propositions for both the attempts and examine them through some case studies. Although we cannot deny that the method of case study does not have strong verifiability, we can provide circumstantial piecses of evidences to support our propositions with the anecdata. We reckon that the propositions we provided still need to be tested with sufficient data in future.

This study shed lights on the process of changeability and un-changeability in institutionalized practices in the context of traditional Japanese HRM, and the research made clear the followings. First, the lifetime employment practice tends to be maintained more strongly in the integraltype technology industry than in the modular-type technology one, which implies that the extent to which management practices are embedded to organizations differs in the industry which they belong to. Second, the lifetime employment practice is embedded as a tacit agreement between companies and mainline members in the parent of company group. The lifetime employment is really a kind of established interest of core male workers. The smaller the portion of blessed male employees, the stronger their unconscious endeavor to maintain the practice in the organizations becomes. Third, although foreigner corporate managers try to put pressures to change HRM practices, their attempts tend to be a failure because of the resistance from the established interesting group in organizations. Forth, the intensity of attempts to change traditional employment practices will be higher in such manufacturers like electronic equipment producers who are in face with rapid technological change. Finally, expanding volume of 
overseas activity demands drastic change in the traditional HRM practices in payment methods in large Japanese manufacturers. However, at the same time, strategic shifts in the remuneration policy have a possibility to expand the volume of overseas activities interactively. The comprehensive meaning of these findings is that the environmental factors of the macroeconomic environment, which is becoming increasingly global, require the deinstitutionalization of traditional employment practices of large Japanese manufacturing companies, while the organizational inertia in the firms in Japan is strengthening the institutionalization of the traditional employment practices. As globalization of the Japanese economy continues to advance, Japanese firms need to change traditional employment practices to conform to global standards. In order to realize the reform, it is necessary to promote a larger deinstitutionalizing factor that surpasses the organizational inertia of trying to preserve the traditional structure of Japanese companies. Among these factors, the one with the most transforming power will be the new technology in industries and the shift of official language in Japanese firms from Japanese to English. Therefore, policy makers should make strategies that shift the labor force from the old technology industry to the one with new technology, and measures to improve the English skills of Japanese workers to enhance the competitiveness of Japanese companies in the global market.

Despite these academic contributions, this study has some limitations. One of the biggest challenges is that the propositions raised in this paper are not statistically verified. This challenge remains as a future research topic.

\section{REFERENCES}

Abegglen, J. (1958). The Japanese factory: Aspects of its social organization. Glencoe, Scotland: Free Press.

Ahmadjian, C. L., \& Robinson, P. (2001). Safety in numbers: Downsizing and the deinstitutionalization of permanent employment in Japan. Administrative Science Quarterly, 46(4), 622-654. doi:https://doi.org/10.2307/3094826

Daily Iron Newspaper. (2015). JFE steel reviews personnel and wage system: Raise treatment for young leaders. Retrieved from https://bit.1y/2Ppwioo

D'aunno, T., Succi, M., \& Alexander, J. A. (2000). The role of institutional and market forces in divergent organizational change. Administrative Science Quarterly, 45(4), 679-703. doi:https://doi.org/10.2307/2667016

DiMaggio, P. J., \& Powell, W. W. (1983). The iron cage revisited: Institutional isomorphism and collective rationality in organizational fields. American Sociological Review, 48(6), 147-160. doi:https://doi.org/10.2307/2095101

Greenwood, R., \& Hinings, C. R. (1996). Understanding radical organizational change: Bringing together the old and the new institutionalism. Academy of Management Review, 21(4), 1022-1054. doi:https://doi.org/10.5465/amr.1996 .9704071862

Jacoby, S. M. (2018). The embedded corporation: Corporate governance and employment relations in Japan and the United States. Princeton, NJ: Princeton University Press.

Kraatz, M. S., \& Moore, J. H. (2002). Executive migration and institutional change. Academy of Management Journal, 45(1), 120-143. doi:https://doi.org/10.5465/3069288

Maguire, S., \& Hardy, C. (2009). Discourse and deinstitutionalization: The decline of DDT. Academy of Management Journal, 52(1), 148-178. doi:https://doi.org/10.5465/amj.2009.36461993

Mahdieh, O. (2015). Interaction between communication and organizational conflict and its relationship with performance. International Journal of Business and Administrative Studies, 1(2), 54-60. doi:https://dx.doi.org/10.20469/ijbas.10002 $-2$

Meyer, J. W., \& Rowan, B. (1977). Institutionalized organizations: Formal structure as myth and ceremony. American Journal of Sociology, 83(2), 340-363. doi:https://doi.org/10.1086/226550

Olcott, G. (2009). Conflict and change: Foreign ownership and the Japanese firm. Cambridge, UK: Cambridge University Press.

Oliver, C. (1992). The antecedents of deinstitutionalization. Organization Studies, 13(4), 563-588. doi:https://doi.org/ $10.1177 / 017084069201300403$

Orru, M., Biggart, N. W., \& Hamilton, G. (1997). The economic organization of East Asian capitalism. New York, NY: Sage.

Perkmann, M., \& Spicer, A. (2008). How are management fashions institutionalized? The role of institutional work. Human Relations, 61(6), 811-844. doi:https://doi.org/10.1177/0018726708092406

Powell, W. W., \& DiMaggio, P. J. (2012). The new institutionalism in organizational analysis. Chicago, IL: University of Chicago Press. 
Rijal, S. (2016). The influence of transformational leadership and organizational culture on learning organization: A comparative analysis of the IT sector, Thailand. Journal of Administrative and Business Studies, 2(3), 121-129. doi:https:// doi.org/10.20474/jabs-2.3.3

Scott, W. R. (2013). Institutions and organizations: Ideas, interests, and identities. New York, NY: Sage Publications.

Silva, H. M. S. V., \& Madushani, R. A. I. (2017). The impact of human resource competencies of front line employees on tourist arrivals of unclassified hotels in Western Province, Sri Lanka. Journal of Advanced Research in Social Sciences and Humanities, 2(1), 9-16. doi:https://doi.org/10.26500/jarssh-02-2017-0102

Toyota. (2018). Toyota way 2001/Toyota code of conduct. Retrieved from https://bit.1y/2s689e2 (Accessed on 14 November, 2019)

Tsai, M. S., \& Tsai, M. C. (2017). The influence of loyalty, participation and obedience on organizational citizenship behavior. International Journal of Business and Economic Affairs, 2(1), 67-76. doi:https://doi.org/10.24088/ijbea-2017-21009

Yin, R. K. (2017). Case study research and applications: Design and methods. New York, NY: Sage Publications.

Zucker, L. G. (1977). The role of institutionalization in cultural persistence. American Sociological Review, 42(5), $726-743$. doi:https://doi.org/10.2307/2094862 